\title{
A RELAÇÃO INTERSUBJ ETIVA ENTRE O ENFERMEIRO E A CRIANÇA COM DOR NA FASE PÓS-OPERATÓRIA NO ATO DE CUIDAR ${ }^{1}$
}

\author{
The intersubj ective relationship between nurse and child \\ with pain in post-surgical fase in the caring act \\ La relación intersubj etiva del enfermero y el niño con dolor \\ no periodo pos-operatorio en acto de cuidar
}

Karin Rosa Persegona ${ }^{2}$

Ivete Palmira Sanson Zagonel ${ }^{3}$

\begin{abstract}
Resumo
Pesquisa qualitativa que tem como questão norteadora "como se processa a relação intersubjetiva estabelecida entre 0 enfermeiro e a criança com dor na fase pós-operatória no ato de cuidar?" baseada na Teoria Humanística de Paterson e Zderad pelo método exploratório-descritivo. Os objetivos foram identificar a relação intersubjetiva estabelecida no ato de cuidar e desvelar como se desenvolve o cuidado do enfermeiro à criança com dor na fase pós-operatória. As informaçoes foram coletadas com oito enfermeiros pela entrevista semi-estruturada gravada. Utilizou-se a Análise Textual Qualitativa proposta por Moraes (2003). Da análise emergiram três categorias e seis unidades de significado. Conclui-se que ser sensível ao sofrimento do outro, fazer-se presente, saber ouvir, tocar, relacionar-se, requer aproximação, na perspectiva de perceber os aspectos subjetivos da criança, a maneira como reage física e emocionalmente ao sofrimento que a dor Ihe proporciona. 0 cuidado humanístico deve ser delineado a partir da percepção multidimensional da experiência existencial de dor.
\end{abstract}

Palavras-chave: Cuidado da Criança. Relações Enfermeiro-Paciente. Dor Pós-Operatória.

\begin{abstract}
Qualitative research aims to respond the guiding question "how is intersubjective relationship estabilished during nursing care to a child in post-surgical phasis pain?" whiting de Paterson and Zderad's Humanistic Theory (1979) carried out a descriptive-exploratory approach. The objectified to identify intersubjective relationship brought about during caring action as well as to unveil how nursing care is undertaken to a child in post-surgical phasis pain. Information was gathered with eight nursesby means of a recorded semi-structured interview. Qualitative Text Analysis proposed by Moraes (2003) was used for the analytical process of the accounts. Three categories emerged from that analysis with six units of meaning. It deems to be sensitive to others' suffering, to be present, to know how to listen, to touch, to relate, it requires to get closer in order to perceive a child's subjective features, how he/she reacts physically and emotionally to suffering from pain. That humanistic nursing care must be delineated from a multidimensional perception of the existential pain experience that a child undergoes.
\end{abstract}

Keywords: Child care. Nursing-child relationship. Pain postoperative

\section{Resumen}

Pesquisa cualitativa que tiene como la cuestión principal "como se procesa la relación intersubjetiva estabelecida entre el enfermero y el niño con dolor no periodo pos-operatorio en el acto de cuidar?" por la Teoria Humanística de Paterson e Zderad (1979) echa a través del método exploratoriodescriptivo. Los objetivos fueron identificar la relación intersubjetiva establecida em el acto de cuidar y revelar como se desenvuelve el cuidado del enfermero al niño com dolor no periodo pos-operatorio. Las informaciones fueron recogidas con ocho enfermeros por medio de la entrevista semiestructurada grabada. Del análisis surgieron tres categorías y seis unidades de significado. Concluí-se que ser sensible al sufrimient del otro, hecerse presente, saber oir, tocar relacionarse; requiere aproximación, em la perspectiva de percibir sensiblemente los aspectos subjetivos Del niño, la manera como reacciona física y emocionalmente al sufrimiento que el dolor le proporciona. El cuidado humanístico del enfermero debe ser delineado a partir de la percepción multidimensional de la experiencia existencial Del dolor. 


\section{INTRODUÇÃO}

As inquietações que surgiram da experiência profissional delinearam o propósito de pesquisar, à luz da teoria da enfermagem humanística de Paterson e Zderad, sobre o cuidado do enfermeiro à criança com dor na fase pós-operatória, como extrato da dissertação de Mestrado em Enfermagem, por vislumbrá-lo como um processo humanístico em que se torna premente a relação intersubjetiva, estabelecida a partir do envolvimento comprometido do enfermeiro; atendendo às necessidades multidimensionais do ser criança que a vivencia ${ }^{1}$.

Cuidar de uma criança em sua vivência de dor requer do enfermeiro habilidades peculiares, que representam sua subjetividade, sua maneira singular de cuidar, seu eu interior. Requer uma reflexão sobre o papel de ser enfermeiro, e uma percepção apurada de quem é o ser cuidado, suas relações, seu mundo interior e exterior, seus familiares/significantes, sua maneira singular de ser criança que vivencia e padece de dor no crítico período pós-operatório.

Ser sensível ao sofrimento do outro, fazer-se presente, saber ouvir, tocar, relacionar-se, requer aproximação, na perspectiva de perceber sensivelmente os aspectos subjetivos da criança, a maneira como reage física e emocionalmente ao sofrimento que a dor the proporciona. É preciso reconhecer a singularidade de sua experiência, num diálogo intuitivo entre os envolvidos, em que as percepções são captadas pela subjetividade de ser enfermeiro. Não há palavras ou protocolos pré-estabelecidos. Cada vivência é única e o cuidado é delineado a partir de percepções genuínas, que atendem as necessidades da criança de uma forma muito particularizada, humanizada, numa relação EU-TU2.

0 cuidado humanístico do enfermeiro deve ser delineado a partir da percepção multidimensional da experiência existencial de dor que a criança vivencia. Esta percepção abrange a observação dos sinais que seu corpo apresenta, alterações fisiológicas que indicam o sofrimento físico. No entanto, ouvir a criança sobre sua dor é permitir que participe de seus cuidados, que relate como se sente e como estes sentimentos afetam sua vida; pois este saber the é próprio, constituído por vivências anteriores e pelo momento e espaço em que está experienciando, numa relação EU-ISSO.

A intervenção cirúrgica caracteriza-se como um procedimento invasivo e, dessa forma, traumático por estimular as fibras nociceptivas, gerando, conseqüentemente, a dor aguda na fase pós-operatória, que se caracteriza como umas das prioridades no cuidado à criança neste momento, por interferir diretamente no seu restabelecimento ao afetar as suas necessidades humanas básicas da criança, como o sono, repouso, alimentação e interação.

Dessa forma, exige um cuidado diferenciado, individualizado para cada criança, e de forma precoce, ou seja, já no período pós-operatório imediato, momento em que desperta da anestesia a que foi submetida. Os primeiros cuidados são prestados na unidade de recuperação pósanestésica, contemplando a avaliação da dor, posto que é reconhecida como o quinto sinal vital, pela importância da sua avaliação e cuidados direcionados ao seu alívio. Essa intervenção precoce é realizada na perspectiva de proporcionar 0 bem-estar 0 estar melhor; metas da Enfermagem, conforme preconizam as teoristas Paterson e Zderad. 0 alívio da dor possibilita à criança condições para restabelecer-se adequadamente, 0 que atende aos princípios da humanização e da ética que deve permear o cuidado do enfermeiro.

A experiência profissional aponta que persiste uma lacuna no cuidado do enfermeiro no manejo da dor na fase pósoperatória no sentido de fornecer alivio e melhoria das condições da criança em sua singularidade de ser, para enfrentar a intervenção cirúrgica em fase tão precoce de sua vida, ou seja, estabelecer o cuidado. Nem todos os enfermeiros possuem clareza, entendimento e até conhecimento específico sobre sua potencial atuação no cuidado intersubjetivo à criança com dor na fase pós-operatória, o que gera déficits de cuidado. 0 controle da dor na fase pós-operatória e o alívio do sofrimento são essenciais para a assistência integral do paciente cirúrgico, e de responsabilidade e compromisso do profissional da área da saúde 3 .

Nesse sentido, este artigo visa identificar a relação intersubjetiva estabelecida no ato de cuidar e desvelar como se desenvolve o cuidado do enfermeiro à criança com dor na fase pós-operatória.

\section{REFERENCIAL TEÓRICO}

A busca por uma interação enfermeiro-paciente diferenciada, por meio da compreensão de como ela se estabelece, impulsionou as enfermeiras Josephine E. Paterson e Loretta T. Zderad a desenvolverem a Teoria da Enfermagem Humanística e apresentarem um novo conhecimento para a ação da Enfermagem. Caracteriza-se como enfermagem humanística por preocupar-se com as experiências fenomenológicas dos indivíduos, a exploração das experiências humanas, sendo as teoristas fortemente influenciadas pelas abordagens filosóficas da fenomenologia e do existencialismo, ao buscar compreender a natureza humana e a enfermagem. Descrevem que "a enfermagem é uma resposta aos males da condição humana [ ...]. Um ser humano necessita certo tipo de ajuda e o outro a proporciona"2:29. 0 existencialismo aparece na teoria como uma experiência existencial que permite 0 conhecimento humano do ser e da qualidade do ser do outro. A teoria humanística tem uma abordagem filosófica para a compreensão da vida, da dimensão do ser humano, sendo 0 existir a dimensão primária ${ }^{4}$.

0 enfoque existencial-fenomenológico-humanista da teoria de Paterson e Zderad contempla a percepção do que seja a relação intersubjetiva no cuidado do enfermeiro à criança com dor na fase pós-operatória, momento no qual necessita de ajuda intencional e comprometida, permeada pelo conhecimento específico e valorização do outro, ao percebê-lo como participante da relação de cuidado, por meio das escolhas que possui; o principal objetivo do enfermeiro é proporcionar 0 bem-estar e o estar melhor pelo diálogo vivido. 
Delinear os conceitos que permeiam o marco conceitual do cuidado à criança com dor pós-operatória é aspecto fundamental para estabelecer as metas de cuidado. Assim, 0 conceito de ser humano é o ser criança com dor, único, singular com especificidades, que necessita de ajuda e é influenciado pelas relações inter-humanas em espaço e tempo definidos de acordo com a situação compartilhada. 0 conceito de enfermagem é vivenciado, não pode ser normatizado por regras e rotinas pré-estabelecidas, acontece como presença, encontro, diálogo, intersubjetividade, revela-se como chamado e resposta de pessoa a pessoa. 0 conceito de saúde-doença é abrangente, desloca-se do corpo físico que sente dor para ir ao encontro do ser criança com sofrimento causado pela dor, com sua inteireza de ser e estar necessitado de ajuda, em que o enfermeiro atua de forma intencional e dialógica para oferecer alívio e restaurar 0 bem-estar. 0 ambiente situa-se na instituição hospitalar onde a criança se encontra em pósoperatório imediato ou mediato (durante e após as primeiras 48 horas do ato anestésico-cirúrgico, respectivamente), podendo ser a unidade de recuperação pós-anestésica, unidade de cuidado intensivo ou unidade de internação; compreendese que o fenômeno da dor na fase pós-operatória pode ser experienciado nesses diferentes cenários, no espaço e tempo considerados.

Uma vez colocados os conceitos que permeiam o marco conceitual do cuidado à criança com dor pós-operatória, a partir das idéias de Paterson e Zderad é possível verificar a aplicabilidade de suas proposições para o cuidado humanístico, em que ocorrem interações, mediações, relações afetivas, proximidade, com vistas a proporcionar o bem-estar e estar melhorem uma sintonia dialógica e existencial. Esses conceitos articulados conformam o cuidado de enfermagem, pois aliam a técnica à sensibilidade, as habilidades à humanidade, em um contexto específico de necessidades peculiares; a doença traz, para a vida de todo ser humano, sofrimento e angústia, contudo, faz parte do seu existir. Incita refletir sobre as conseqüências que uma hospitalização, por mais breve que seja, significa para a criança e seus familiares. E mais, o que significa sentir dor, expressão real de sofrimento e angústia vivenciados pela criança e sua família2.

Há que se compreender que existe a dificuldade do paciente em descrever a dor e dos profissionais de saúde conhecerem exatamente a experiência de dor vivenciada pelo outro, pois trata-se de "uma experiência individual, com características próprias do organismo, associada a sua história passada, além do contexto no qual ela é percebida" 5:271. A dor "é 0 que 0 indivíduo que a sente diz ser e existe quando a pessoa que a sente diz existir". Esta afirmação apresenta a necessidade da individualização da avaliação e do tratamento da dor, adequado às queixas e reações de cada indivíduo, posto que cada pessoa sente e reage à sensação dolorosa de forma diferente ${ }^{3: 159}$.

Nesse sentido, o Comitê de Taxonomia da Associação Internacional para o Estudo da Dor (IASP) define a dor como uma experiência sensorial e emocional desagradável que é associada a lesões reais ou potenciais. Destaca que se trata de um fenômeno sempre subjetivo, e cada indivíduo aprende a utilizar este termo por meio de suas experiências vivenciadas ${ }^{3}$

Em pacientes pediátricos, a dor é influenciada e determinada pelo seu nível de desenvolvimento ${ }^{6}$. A maneira como a criança comunica a sua dor e sua habilidade para enfrentá-la está intimamente relacionada à sua idade e maturidade cognitiva. $\dot{A}$ medida que se desenvolve, a criança enfrenta e exibe comportamentos que sinalizam a presença de dor, e esta afirmação pode ser observada em bebês (choro, caretas e posturas corporais) e crianças maiores, que podem se queixar de outras formas de dor ao falar sobre ela com outras pessoas, principalmente as mais significantes, as quais julga poderem tomar providências para aliviá-la ${ }^{6}$.

0 paciente pediátrico pode sentir dor devido a muitos procedimentos que são necessários durante a hospitalização, como punção venosa, coleta de exames laboratoriais, trocas de curativos, entre outros. No entanto, na necessidade de um procedimento cirúrgico, a prevalência é aumentada, conseqüência da própria manipulação das estruturas nervosas do organismo. A possibilidade de realizar uma cirurgia pediátrica permitiu o progresso no tratamento das doenças, todavia, a dor é conseqüência inevitável na maioria dos atos cirúrgicos, sendo caracterizada pela dor na zona operatória (tração e incisão cutâneas, às vezes musculares e aponeuróticas), máxima nas primeiras horas do pós-operatório, e dores pós-operatórias por mobilização, que se adicionam às dores da zona operatória com a manipulação e cuidados com sondas, cateteres e drenos ${ }^{7}$

0 período pós-operatório, iniciado na admissão do paciente na unidade de recuperação anestésica (pós-operatório imediato), estende-se até a avaliação de seguimento de seu restabelecimento na unidade de origem (internação) ou no domicílio (pós-operatório tardio); é caracterizado por cuidados de enfermagem relacionados à avaliação dos efeitos dos agentes anestésicos, à monitorização das funções vitais, à prevenção das complicações e à observação e intervenção na queixa de dor ${ }^{8}$.

Destaca-se neste período a complexidade dos cuidados realizados pelo enfermeiro e sua equipe. Dentre eles, merece atenção especial o controle do estímulo doloroso, caracterizado como dor aguda, ou seja, aquela relacionada às afecções traumáticas, infecciosas ou inflamatórias, com expectativa de desaparecimento após a cura da lesão, tendo respostas neurovegetativas associadas à ansiedade e à agitação psicomotora freqüentemente presentes. Apesar de ser um sintoma, a dor hoje é considerada o quinto sinal vital, pela exigência que deve ser dada na sua avaliação e no seu registro?.

A Joint Comission on Accreditation on Healthcare Organizations (JCAHO) publicou em janeiro de 2000 uma norma que estabelece e descreve a dor como quinto sinal vital e que, portanto, deve ser sempre avaliada e registrada simultaneamente aos demais sinais vitais, visando conhecer a conduta tomada, sua razão e resultados obtidos. ${ }^{5} \mathrm{~A}$ dor deve sempre ser tratada, pois, ao contrário, pode atrasar o processo de cura dos tecidos e a recuperação da criança, causando 
ansiedade, depressão, irritabilidade e exaustão, interferindo nas necessidades básicas relativas à alimentação e sono. Acrescenta que dores não controladas tornam a criança medrosa e podem provocar alterações cerebrais que tornam ainda piores as dores futuras ${ }^{6}$.

Outros aspectos que colaboram para a avaliação da dor são as observações quanto às reações comportamentais e fisiológicas apresentadas pela criança no pós-operatório, incluindo expressão facial, inquietação, por vezes imobilidade, posicionamento protetor, insônia, ansiedade, irritabilidade, sudorese, palidez, taquicardia, taquipnéia, hipertensão, entre outros ${ }^{5}$.

0 relato da criança sobre sua dor também merece destaque durante a avaliação, pois "as expressões vocais ou faciais da dor ou a atividade motora podem ser avaliadas. Os choros são a primeira expressão vocal da dor ${ }^{\prime 10: 279}$. No entanto, a expressão da dor pode ser modificada pelos fatores culturais da subjetividade ou ligadas ao ambiente ${ }^{7}$, 0 que destaca a subjetividade como uma dimensão que não pode deixar de ser considerada durante a avaliação da dor em crianças.

É importante reconhecer que, ao realizar o levantamento das necessidades de cuidado da criança que vivencia a dor na fase pós-operatória, 0 enfermeiro deve estar consciente das interações que se estabelecem, aspecto de impacto nos resultados e resposta à dor pela criança, ou seja, há uma interação das dimensões objetivas e subjetivas que resultam na sensação dolorosa.

A dimensão objetiva é compreendida por abranger as necessidades de cuidado que são diretamente detectáveis, mensuráveis, que podem ser observadas de forma objetiva pelos profissionais da saúde, ao realizarem os cuidados à criança com dor na fase pós-operatória. Como exemplos dessas necessidades de cuidado, podem-se entender a extensão e a profundidade da incisão cirúrgica, a alteração dos sinais vitais, que é decorrente da própria agitação psicomotora e do quadro álgico vivenciado, a fisionomia da criança, medicações administradas, entre outros.

Consideramos, também, a mais fácil de ser efetivada, pois é voltada à ação prática de alívio da dor, utilizando drogas medicamentosas que inibem o seu aparecimento e manutenção. Porém, apenas essa ação não é suficiente para considerar a criança como ser humano, pois, em volta da dor, podem estar velados os chamados para o cuidado, que necessitam de respostas eficientes para perceber a subjetividade que permeia a relação profissional-criança durante o cuidado.

A consideração da dimensão subjetiva envolve 0 reconhecimento das experiências, da história de vida, valores, sentimentos, emoções, crenças, interações, diálogo, a intimidade da criança com dor, aquilo que lhe é próprio. Essas necessidades de cuidado serão identificadas a partir do momento em que a subjetividade for expressada, por meio do reconhecimento da sua existência e do estabelecimento da relação intersubjetiva, isto é, da relação sujeito-sujeito, que possibilita conhecer a pessoa em sua individualidade singular².

Entendemos também a subjetividade como um fator que está diretamente relacionado à dor na fase pós-operatória, sendo expressa tanto pela criança, ou seja, como percebe e reage ao fenômeno, quanto pelo enfermeiro, como concebe e realiza os cuidados. Esse encontro de subjetividades no processo de cuidar proporciona que ambas as dimensões sejam expressas e ultrapassa o olhar objetivo do cuidado (baseado em dados verificáveis e mensuráveis), por valorizar o sensível, a percepção mais íntima da criança em relação à sua vivência e experiência dolorosa, ou seja, a subjetividade, por meio do estabelecimento de uma relação intersubjetiva.

A dimensão subjetiva ainda é deficiente no sistema atual de cuidado, pois em geral as equipes estão preocupadas coma técnica cirúrgica, com o sucesso da cirurgia, dedicando pouca atenção ao cuidado na fase pós-operatória. 0 cuidado no período pós-operatório cabe, quase que inteiramente, ao bom desempenho do profissional enfermeiro, que, ao cuidar, necessita de suas habilidades técnicas, mas também da sensibilidade para detectar o que se esconde por trás da dor em uma criança.

A partir dessa contextualização, percebemos a extensão do trabalho dos enfermeiros que cuidam de crianças no período pós-operatório em relação à dor e a necessidade de subsidiar sua prática profissional para cuidar da criança de maneira a considerar a subjetividade que permeia a relação enfermeirocriança-família, no sentido de diminuir a ansiedade e sofrimento vivenciados.

\section{METODOLOGIA}

Para efetivar a pesquisa utilizamos a abordagem qualitativa, por meio do método exploratório-descritivo. Como técnica de coleta das informações, aplicamos a entrevista semiestruturada gravada, realizada no período de março a julho de 2007, com oito enfermeiros atuantes em seis distintas unidades de cuidados pós-operatórios de um hospital infantil de grande porte de Curitiba, que é referência na América Latina em saúde da criança. Os discursos que permearam a análise foram identificados com a sigla $\mathrm{E}$ (enfermeiro), seguida de um número arábico segundo a ordem cronológica da realização da entrevista.

Atendendo aos aspectos éticos, o projeto foi aprovado no CEP da instituição contexto da pesquisa sob o N. 0360/06, e todos os enfermeiros assinaram o Termo de Consentimento Livre e Esclarecido (TCLE). As entrevistas foram transcritas na íntegra, e os discursos receberam uma identificação representada pela letra $D$, seguida de um número, de acordo com a ordem cronológica da realização das mesmas.

A análise dos discursos foi realizada por meio da análise textual qualitativa ${ }^{10}$, que compreendeu três etapas: a desmontagem dos textos (desconstrução e unitarização); 0 estabelecimento de relações (processo de categorização) e a captação do novo emergente (expressão das compreensões atingidas). 


\section{RESULTADOS OBTIDOS}

Por meio da efetivação da primeira etapa da análise textual qualitativa ${ }^{11}$, desmontagem dos textos (desconstrução e unitarização), e da segunda etapa, o estabelecimento de relações (o processo de categorização), foi possível construir três categorias distintas de análise e seis unidades de significado. Para este artigo, destacamos a categoria 0 diálogo intuitivo ao ver, ouvir e sentir o outro numa relação EU-TU: 0 encontro de subjetividades; a qual foi construída a partir das seguintes unidades de significado: "A subjetividade de ser enfermeiro que cuida da criança com dor pós-operatória"; "A subjetividade da criança que vivencia a dor pós-operatória" e "A vivência da relação intersubjetiva do enfermeiro e criança com dor pós-operatória".

A análise textual qualitativa da categoria 0 diálogo intuitivo ao ver, ouvir e sentir o outro numa relação EU-TU: 0 encontro de subjetividades proporcionou atingir a compreensão de que a relação intersubjetiva do enfermeiro e criança com dor pós-operatória é uma condição essencial para que 0 cuidado humanizado e multidimensional aconteça. É estabelecida a partir do momento em que há o reconhecimento, proporcionado pelo conhecimento intuitivo, pela relação EUTU estabelecida, das subjetividades de ambos como dimensões que lhes são próprias, inerentes ao seu ser, e que merecem, portanto, ser consideradas. Dessa forma, criança e enfermeiro, juntos, estabelecem o cuidado, de acordo com suas perspectivas de como este deve ser realizado, para que se torne um ato genuíno, efetivo, em que a criança possa vir-aser, ou seja, experimentar saúde, confor to, alívio da dor².

Contribui [para o cuidado] porque, como a proximidade acaba aumentando muito mais, então o cuidado acaba sendo mais humanizado e isso melhora muito na assistência. E aumenta muito 0 retorno pra mim como profissional, de saber que aquela criança está recebendo uma assistência de qualidade, humanizada, e que está deixando de sentir dor naquele momento (E6).

A dor é reconhecida como um desafio, como algo a ser continuamente explorado na prática profissional do enfermeiro, como uma necessidade de cuidado que deve ser considerada pelas conseqüências que pode proporcionar à criança que a vivencia. Dessa forma, em seu processo de cuidar, o enfermeiro imprime sua forma singular de ser, sua maneira de conceber a dor na fase pós-operatória, bem como a forma como percebe a criança que está sob seus cuidados. Busca vivenciar cada encontro como algo próprio, como um indivíduo singular, como um ser aqui e agora; e isto caracteriza a sua subjetividade.

E olhar pra criança, a criança está chorando, a gente acha que ela está com dor, específica da cirurgia, e já quer dar uma medicação, mas tem que ser muito mais do que isso, né? A gente tem que ter flexibilidade pra perceber o que realmente aquela criança está precisando (E5).
[...] nós precisamos da prescrição, mas tem toda essa parte subjetiva que envolve [a dor], se não tiver isso, sinceramente nós vamos nos tornar máquinas. Por que nós cuidamos? (E7).

A percepção de si como um ser multidimensional, que necessita de atenção, de afeto e respeito, caracteriza 0 enfermeiro como o membro da equipe de saúde sensível às necessidades subjetivas da criança. Isso revela que, para poder perceber 0 outro em suas particularidades, é necessário perceber a si mesmo. Essa compreensão o leva a realizar um cuidado humanizado, pois consegue vislumbrar 0 outro e a si mesmo como seres com necessidades de diversificadas dimensões.

A subjetividade do enfermeiro foi vista como um fator de reconhecimento profissional, pois possibilita a sensibilização para um cuidado mais humano como um ser multidimensional, que precisa de reconhecimento, de retorno positivo, ao perceber que seu cuidado é humanizado, de qualidade, e é efetivo na resposta ao chamado de cuidado.

A subjetividade da criança, no entanto, constitui aspecto fundamental para o cuidado à dor que a mesma vivencia. Portanto, os cuidados deverão ser direcionados para 0 atendimento das necessidades singulares que ela apresenta. Uma abordagem unidirecional de cuidado não é suficiente para uma vivência tão íntima e complexa que é a dor; devendo, portanto, sensibilizar-se para os aspectos subjetivos que a determinam.

Tem criança que é mais lenta na resposta [à dor], tem criança que é rápida. Assim como nós, eu não sou tão sensível à dor como algumas pessoas, mas tem gente que é muito sensivel à dor. E é isso que a gente aprende quando estuda a dor, que cada um tem o seu tipo de dor, cada um sente da sua forma. Então, não adianta eu generalizar (E7).

0 importante é realmente que a enfermeira tenha muita sensibilidade, que trabalhe voltada para 0 cuidado do bebê, avaliando-o sempre como um ser único, porque às vezes a gente tem duas crianças com a mesma patologia e cada uma reage de um jeito. Então, nunca generalizar (E7).

0 reconhecimento da subjetividade da criança, da sua forma singular de ser, da maneira como se relaciona com os demais seres humanos, de como enfrenta as dificuldades do cotidiano, deve ser realizado a partir do momento em que se considera 0 relato da mesma sobre a dor na fase pós-operatória que vivencia. Dessa forma, torna-se ativa e participante de seus cuidados à medida que consegue relatar a eficácia ou não, subsidiando 0 enfermeiro em suas ações de cuidado, seus avanços e retrocessos.

A consideração pelo relato da criança que vivencia a dor na fase pós-operatória foi visto como um ato essencial para um cuidado humano genuíno, um diálogo vivido. Caso contrário, a relação não se estabelece, quando a criança, por exemplo, 
percebe que sua subjetividade não está sendo respeitada. Dessa forma, não se criam vínculos de confiança, de respeito, e conhecê-la mais intimamente, sua subjetividade, torna-se uma tarefa difícil.

Eu acho o relato muito importante, porque a criança é coerente, sincera, então você começa a perguntar e ela te diz se dói, se não dói, ou se ela está com medo. Então, a gente procura conversar com bastante carinho com ela; ou até mesmo brincar pra tentar distrair esse medo que tem do branco, do enfermeiro. Então, tem que começar, pois à medida que a gente conquista a criança, ela fala tudo (E2).

Quando a criança consegue se comunicar com a equipe, isto deve ser levado em consideração sempre e acima de qualquer coisa, pois nos trará dados fundamentais para tomarmos a conduta mais adequada. Ela vai nos dizer que tipo de dor é, se é contínua, se é tipo fisgada, se é como se fosse uma picada ou um ressentimento. Então, estes dados são importantes, são detalhes [...] e o detalhe é que faz a diferença (E8).

Para tanto, 0 uso de uma linguagem mais acessível ao entendimento da criança que vivencia a dor na fase pósoperatória é uma condição essencial para que o encontro das subjetividades aconteça. A aproximação do enfermeiro à criança por meio de um diálogo acessível ao seu nível de desenvolvimento deixa-a mais segura e confiante para relatar a experiência de dor que vivencia, e em quais aspectos de sua vida está sendo determinante. Dessa forma, 0 enfermeiro consegue levantar as necessidades de cuidado, partindo para o julgamento clínico e posterior tomada de decisões sobre seu agir.

\section{CONSIDERAÇÕES FINAIS}

Foi possivel atingir a compreensão de que a relação intersubjetiva permite inovar o cuidado do enfermeiro à criança com dor na fase pós-operatória. Considerar a subjetividade como aspecto inerente ao ser humano, neste contexto à criança que padece de dor, é dar visibilidade ao processo de cuidar do enfermeiro, a partir do momento em que as ações de cuidado tornam-se mais efetivas, decorrentes das respostas sensiveis, porém assertivas, e às complexas necessidades que envolvem a experiência de dor da criança no período pós-operatório.

Nessa teia de relações, EU-TU, EU-ISSO, foi tecido um forte vínculo de afetividades, entrelaçada pelo diálogo vivido, intersubjetividade, presença genuína, visando o bem-estar e estar melhor, pela atenção aos chamados e respostas precisas à situação vivenciada. Percebemos o envolvimento dos enfermeiros ao avaliar a dor, ultrapassando a dimensão instrumental de cuidar, efetivando de diferentes formas a dimensão expressiva.

0 trabalho desenvolvido com crianças exige competência do enfermeiro, e se ela estiver com dor, o cuidado deve ser desencadeado por circunstâncias reais de necessidades diante da fragilidade, da capacidade restrita de reações da criança, para um nível de compreensão fenomenológica, existencial do ser criança com dor.

A intersubjetividade é observada nos depoimentos como for te componente que acompanha as ações cuidativas diante da dor. Ressaltam a necessidade de ir até a criança, ver como está, sentir suas emoções, tornar-se presença genuína, reconhecer a singularidade de cada ser. A subjetividade é aquilo que mais temos de peculiar, de singular, que caracteriza uma marca individual, pessoal, é o modo como configuramos a apreensão da realidade. A subjetividade é vivenciada individualmente de acordo com a história de cada ser envolvido, o que faz com que cada pessoa sinta, diferentemente do outro, a mesma situação.

É essa subjetividade que torna os enfermeiros diferentes diante do fenômeno dor na criança, em que cuidam considerando seus valores e crenças, sua maneira própria de ser, em que cada um busca aliviar a dor de uma forma, que se configura como existencial, que se revela naquele compromisso de elevado significado. A realidade existencial do enfermeiro se entrecruza com a realidade existencial do ser criança com dor, configurandose em co-existência de subjetividades.

Percebo que a compreensão do fenômeno dor na criança é uma construção gerada pelo curso das idéias que se combinam no pensamento em uma relação íntima com o problema estudado. A compreensão permite a produção de conhecimento com real valor aos diálogos que nela se desenvolvem e nos quais os sujeitos se envolvem emocionalmente produzindo resultados de grande significado para a área de enfermagem. Assim, quando o enfermeiro considera a criança com singularidade, a identifica de forma única em sua constituição subjetiva, com seus processos culturais, seu mundo interno e externo, seu modo social de viver.

A qualidade e a complexidade das informações obtidas na pesquisa, aliadas ao referencial teórico de Paterson e Zderad e à experiência profissional, ofereceram a sustentação teórica para chegar aos resultados, que abrem um leque de possibilidades e novas inquietações.

Entre as possibilidades damos relevância ao desvelado, ao dito pelos sujeitos, à forma como se expressam quando se referem ao cuidado, às distintas dimensões envolvidas que são constituídas de subjetividade.

Os achados não representam um marco acabado e estático, mas é um movimento, uma construção, a partir das informações obtidas, que devem ser consideradas um processo investigativo tendo como alvo o ser criança com dor.

Aos enfermeiros recomendamos que se apropriem de referenciais teóricos e metodológicos que dêem sustentação às suas ações de cuidado à criança com dor na fase pósoperatória, para que suas tarefas tornem-se importantes e de significado científico. Aos centros formadores, que incorporem a intersubjetividade em seus programas curriculares, para que possam ensinar aos futuros profissionais a arte de lidar com elas. Aos serviços de saúde, que tenham em suas estratégias gerenciais ações que privilegiem o sujeito do cuidado para que, assim, a atenção torne-se personalizada, individualizada, favorecendo a recuperação em sua integralidade. 


\section{Referências}

1. Persegona KR. Relação intersubjetiva do enfermeiro e a criança com dor pós-operatória [dissertação]. Curitiba (PR): Universidade Federal do Paraná - Programa de Pós-Graduação em Enfermagem; 2007.

2. Paterson JE, Zderad LT. Enfermería humanística. México: Limusa; 1979.

3. Chaves LD, Leão ER. Dor 0 50 sinal vital: reflexões e inter venções de enfermagem. Curitiba (PR): Maio; 2004.

4. Santos MCL, Pagliuca LMF, Fernandes AFC. Cuidados paliativos ao portador de câncer: reflexões sob o olhar de Paterson e Zderad. Rev Latino-am Enfermagem. 2007; 15(2): 350-355.

5. Pedroso RA, Celich KLS. Dor: quinto sinal vital, um desafio para o cuidar em enfermagem. Texto e Contexto Enferm. 2006. 15(2): 32 49.
6. Claro MT. Dor em pediatria. In: Chaves LD, Leão ER. Dor 050 sinal vital: reflexões e intervenções de enfermagem. Curitiba (PR): Maio; 2004. p.208-218.

7. Eccofey C, Desparmet]. Analgesia na cirurgia pediátrica. In: BONNET E. A dor no meio cirúrgico. 2.ed. São Paulo(SP): Artes Médicas, 1994.

8. Smeltzer SC, Bare BG. Brunner e Suddarth: tratado de enfermagem médico-cirúrgica. Rio de Janeiro(RJ): Guanabara Koogan; 2000.

9. Silva MAPD. Dor: visão biopsicossocial e espiritual da assistência In: Chaves LD, Leão ER. Dor 0 5 sinal vital: reflexões e intervenções de enfermagem. Curitiba (PR): Maio; 2004. p.26-32.

10. Moraes R. Uma tempestade de luz: a compreensão possibilitada pela análise textual discursiva. Ciência e Educação. 2003. 9(2): 191211. 